\title{
Application and Practice of Rubbing Fastness Improver DM-2589N
}

\author{
Lv Xiaolan ${ }^{1,2, ~ *, ~ L i a o ~ H u a n ~}{ }^{1}$, Chen Jianfang ${ }^{1, ~ *, ~ D e n g ~ D o n g h a i ~}{ }^{2}$ \\ ${ }^{1}$ College of Chemistry and Chemical Engineering, Hunan Institute of Engineering, Xiangtan, China \\ ${ }^{2}$ Guangdong Dymatic Chemical Co. Ltd., Foshan, China
}

Email address:

lvxl@dymatic.com (Lv Xiaolan), cjf1228@aliyun.com (Chen Jianfang)

${ }^{*}$ Corresponding author

To cite this article:

Lv Xiaolan, Liao Huan, Chen Jianfang, Deng Donghai. Application and Practice of Rubbing Fastness Improver DM-2589N. World Journal of Applied Chemistry. Vol. 4, No. 1, 2019, pp. 1-6. doi: 10.11648/j.wjac.20190401.11

Received: December 28, 2018; Accepted: February 1, 2019; Published: May 26, 2019

\begin{abstract}
The purpose of this paper is to introduce the application and Practice of a wet rubbing fastness improver DM-2589N in dark cotton fabrics. Methodology - The influence of DM-2589N mass concentration, baking temperature and time on the rubbing fastness are studied. The effects of DM-2589N on different fabrics, different dyes, and the effects of DM-2589N and other finishing agents in the same bath are studied. Findings - DM-2589N has excellent lifting effect on all kinds of cotton fabrics, and it is suitable for the improvement of rubbing fastness of fabrics dyed with reactive, direct, vulcanized and vat dyes. the optimum process is DM-2589N $40 \mathrm{~g} / \mathrm{L}$, One dip and one rolling, baking temperature $150^{\circ} \mathrm{C}$. Practical implications - The dry and wet rubbing fastness of the finish products can be increased above Grade 3-4, which can meet the first-class quality requirements of customers. Originality/value - The wet-rubbing fastness improver DM-2589N can be used in the same bath with the fixing agent and softener without adjusting the $\mathrm{pH}$ value, which can simplify the production process, shorten production time and greatly improve production efficiency.
\end{abstract}

Keywords: Dyeing and Finishing Agent, Rubbing Fastness, Dyed Textiles, Reactive Dyes, Sulfur Dyes, Direct Dyes, Cellulose Fiber

\section{Introduction}

The wet rubbing fastness of dyed textiles, especially deep colored cotton fabrics, usually cannot meet the requirements. Especially, the wet rubbing fastnesses of woolen fabrics and corduroy fabrics are lower than the wet rubbing fastness of cloth fabrics of the same color depth. This is mainly due to the fact that in addition to the color transfer in the testing process, the short velvet on the fabric will also be transferred to the friction head. So it is more difficult to improve the wet rubbing fastness of the pile fabric [1-4].

Rubbing fastness enhancers have been developed in China since the 1990s. After decades of development, progresses have been achieved. Although all of the main domestic auxiliaries manufacturers have products on the market, there is a lack of the all-round rubbing fastness enhancer, with remarkably improved wet rubbing fastness of cashmere fabrics, no selectivity in dyes, little effect on the feel of fabrics, and no need to adjust the $\mathrm{pH}$ value of working fluid in use. Some of the rubbing fastness enhancers on the market are only suitable for fabrics dyed by reactive dyes. And some are good for vulcanized, direct dyed fabrics, which need to be adjusted in use. The $\mathrm{pH}$ value of the working fluid may have the problem of increased color, while the handle of some finished fabrics is hard [5-12].

The rubbing fastness lifting agent DM-2589N is a special kind of high molecular polymer. It does not need to adjust the $\mathrm{pH}$ value of the working fluid in use. By fixing and crosslinking, the direct dyes can be significantly increased by forming films on the fabric. Reactive dyes, sulphide dyes and vat dyes can improve the wet rubbing fastness of fabrics and the wearability of dark textiles. The effects of reactive dyes, sulphide dyes and vat dyes on the wet rubbing fastness of fabrics are significant, and the effects on the color and the feel of fabrics are negligible. 


\section{Experimental}

\subsection{Materials and Instruments}

Cotton standard lining fabric (Shanghai Institute of Textile Industry Supervision) (Shanghai Institute of Textile Industry), cotton, white, pure cotton, white corduroy, pure cotton, white corduroy (for sale in the market); Cotton poplin plain weaving machine (warp yarn count: 40S, weft yarn count: $40 \mathrm{~S}$ ), whole cotton twill yarn card (warp yarn number: $32 \mathrm{~s}$, weft yarn count: $32 \mathrm{~s}$, market).

Reagents and drugs: rubbing fastness promoters DM-2589N, active fixing agent DM-2517, silicone oil, film, DM-2230, homogenate, DM-2230, Nonionic osmotic agent DM-1230 (Guangdong Demei Hi-tech material Co., Ltd); active emerald blue BES150\% (C. I. Active blue 21; active Tibetan green BF (multicomponent compound, Zhejiang intercalated soil co., Ltd.); active black RG 100\% (C. I. Active black 5), active super red RW 200\% (C. I. Active red 264), direct suntan resistance G100\% (C. I. Direct black 4BS was 100\% (C. I. Direct blue BRL100\% (C. I. Direct blue 200; sulfur black 100\% (C. I. BR 100\% (C. I. Reducing brown 1, reducing black RB 100\% (C. I. Reduction Black 9; Sulfide, Sodium Carbonate, Sodium Chloride, anhydrous Sodium Sulfate, Sodium hydroxide, Insurance Powder (marketed).

Equipment: type 1: 101A-3 electrothermal blast dryer (Shanghai Laboratory instrument Factory) Type Mi-ECO-24 all-purpose color test machine, small laboratory rolling mill, Laboratory sample setter (Rapid Company) UltraScan VIS computer colorimeter (USA Hunter Lab), meets the requirements of GB/T 3920-2008 rubbing fastness instrument (Wenzhou Fangyuan instrument Company), perspiration fastness instrument (Wenzhou Fangyuan instrument Co., Ltd.).

\subsection{Test Items and Methods}

\subsubsection{Dyeing Formula and Process}

Reactive dyes: $5 \%$ (omf), yuan powder $80 \mathrm{~g} / \mathrm{L}$, soda $25 \mathrm{~g} / \mathrm{L}$, bath ratio 1 : $10,60^{\circ} \mathrm{C}$ dyeing $60 \mathrm{~min}$, water washing, dehydration, drying.

Direct dyes: dye dosage $5 \%$ (omf), yuan powder $5 \mathrm{~g} / \mathrm{L}$, bath ratio $1: 10,100^{\circ} \mathrm{C}$ dyeing $60 \mathrm{~min}$, wash, dehydration, drying.

Sulphide dye: $6 \%$ (omf), sulphide base $5 \mathrm{~g} / \mathrm{L}$, bath ratio 1 : $10,95^{\circ} \mathrm{C}$, dyeing $30 \mathrm{~min}$, adding sodium chloride $5 \mathrm{~g} / \mathrm{L}$ to water washing for $30 \mathrm{~min}$, then dehydrating in air for $10 \mathrm{~min}$, and drying.

Vat dyes: dye dosage of $6 \%$ (omf), caustic soda $5 \mathrm{~g} / \mathrm{L}$, safety powder $10 \mathrm{~g} / \mathrm{L}, \mathrm{DM}-22301.0 \mathrm{~g} / \mathrm{L}$ bath ratio of $1: 10,60^{\circ} \mathrm{C}$ reduction $30 \mathrm{~min}$, dyeing $40 \mathrm{~min}$, wash, hydrogen peroxide $1.0 \mathrm{~g} / \mathrm{L}$ oxidation $10 \mathrm{~min}$, washing, dehydration, drying.

\subsubsection{Finishing Process of Rubbing Fastness Lifting Agent}

The rubbing fastness lifting agent $\mathrm{Xg} / \mathrm{L}$, one dip and one rolling, has a rolling surplus rate of $(80 \pm 5)$ and baking at $150^{\circ} \mathrm{C}$ for $120 \mathrm{~s}$.

\subsubsection{Rubbing Colour Fastness [13]}

According to GB/T 3920-2008, "Color fastness Test for Textiles."

\subsubsection{Fastness to Soaping [14]}

According to GB/T 3921-2008, "Test for colour fastness to soaping".

\subsubsection{Colour Fastness to Perspiration [15]}

According to GB/T 3922-2013, "Textiles color fastness test" test for perspiration fastness.

\subsubsection{Fabric Color Difference Value}

According to CIE standard, the color difference of fabric was measured by Ultra Scan VIS spectrophotometer at D65/10 of light source, and the value of color difference of fabric was measured by using dyed fabric as reference.

\section{Results and Discussions}

\subsection{Influence of DM-2589N Concentration}

The 32 s cotton knitted fabric with direct tanning resistance $\mathrm{G}$ dyed by active Tibetan green $\mathrm{BF}$, was dipped into the rubbing fastness promotion agent DM-2589N 10, 20, 25, 30, $40,50 \mathrm{~g} / \mathrm{L}$, respectively. The color fastness and chromatic difference value $\mathrm{E}$ were tested in Table 1.

Table 1. Friction colour fastness and discoloration value of different dosage.

\begin{tabular}{llllll}
\hline & \multicolumn{2}{c}{ Dyeing cotton fabric with active Tibetan blue BF } & \multicolumn{2}{c}{ Direct black G dyed cotton fabric } \\
\cline { 2 - 6 } Dosage & Delta E value & Dry rubbing colour fastness & $\begin{array}{l}\text { Wet rubbing colour } \\
\text { fastness }\end{array}$ & $\begin{array}{l}\text { Delta E value } \\
\text { Dry rubbing } \\
\text { colour fastness }\end{array}$ & $\begin{array}{l}\text { Wet rubbing } \\
\text { colour fastness }\end{array}$ \\
\hline Blank (0g/L) & 0.56 & 3 & 1 & 0.64 & 3 \\
$10 \mathrm{~g} / \mathrm{L}$ & 0.57 & 4 & $2-3$ & 0.69 & 4 \\
$20 \mathrm{~g} / \mathrm{L}$ & 0.68 & $4-5$ & 3 & 0.70 & $4-5$ \\
$25 \mathrm{~g} / \mathrm{L}$ & 0.71 & $4-5$ & $3-4$ & 0.74 & $4-5$ \\
$30 \mathrm{~g} / \mathrm{L}$ & 0.70 & $4-5$ & 4 & 0.71 & $4-5$ \\
$40 \mathrm{~g} / \mathrm{L}$ & 0.74 & $4-5$ & 4 & 0.76 & $4-5$ \\
$50 \mathrm{~g} / \mathrm{L}$ & 0.77 & $4-5$ & 4 & 0.75 & 4 \\
\hline
\end{tabular}

It can be seen from Table 1 that the wet rubbing fastness of dyed cotton fabrics gradually improved When the mass concentration of DM-2589N increased from $0 \mathrm{~g} / \mathrm{L}$ to $30 \mathrm{~g} / \mathrm{L}$, the color fastness to wet friction of dyed cotton fabrics gradually improved. When the mass concentration of
DM-2589N increased from $30 \mathrm{~g} / \mathrm{L}$ to $50 \mathrm{~g} / \mathrm{L}$, the color fastness to wet friction of dyed cotton fabrics did not increase. The wet rubbing fastness of DM-2589N with mass concentration of $30 \mathrm{~g} / \mathrm{L}$ reached the maximum of 4 grades. This indicates that the optimum mass concentration of DM-2589N is $30 \mathrm{~g} / \mathrm{L}$. 
According to the color difference in Table 1, the rubbing fastness improver DM-2589N has a significant effect on the wet rubbing fastness of cotton fabrics dyed with reactive dyes and direct dyes, and has little effect on the color and light of the fabrics.

\subsection{Effect of Baking Temperature}

$32 \mathrm{~S}$ cotton knitted fabric with direct tanning resistance to black $\mathrm{G}$ dyeing with active Tibetan blue BF, impregnated with $\mathrm{DM}-2589 \mathrm{~N} 30 \mathrm{~g} / \mathrm{L}$, was baked at $130,150,160,170^{\circ} \mathrm{C}$ for $120 \mathrm{~s}$, respectively. The color fastness to wet friction was tested in Table 2 after wetting.

Table 2. Colour fastness to friction at different baking temperatures.

\begin{tabular}{llll}
\hline \multirow{2}{*}{ Baking temperature } & \multicolumn{2}{l}{ Dyeing cotton fabric with active Tibetan blue BF } & \multicolumn{2}{l}{ Direct black G dyed cotton fabric } \\
\cline { 2 - 4 } & Dry rubbing colour fastness & Wet rubbing colour fastness & Dry rubbing colour fastness \\
\hline $130^{\circ} \mathrm{C}$ & $4-5$ & $3-4$ & $4-5$ \\
$150^{\circ} \mathrm{C}$ & $4-5$ & 4 & $4-5$ \\
$160^{\circ} \mathrm{C}$ & $4-5$ & 4 & $4-5$ \\
$170^{\circ} \mathrm{C}$ & $4-5$ & $3-4$ & $4-5$ \\
\hline
\end{tabular}

Table 2 showed that when the baking temperature was raised from $130^{\circ} \mathrm{C}$ to $150^{\circ} \mathrm{C}$, the lifting effect of DM-2589N on wet rubbing fastness of dyed fabrics became better. This was mainly because the increase of temperature that is beneficial to the fully film-forming of DM-2589N. When the baking temperature was $170^{\circ} \mathrm{C}$, the lifting effect of wet rubbing fastness of fabric slightly decreased compared with that of $150^{\circ} \mathrm{C}$ and $160^{\circ} \mathrm{C}$. In addition, extremely high baking temperature exerted serious damage to cotton fiber and largely affected the color and light of fabric. Therefore, the baking temperature after finishing with improver $\mathrm{DM}-2589 \mathrm{~N}$ is determined to be $150^{\circ} \mathrm{C}$.

\subsection{Effect of Curing Time}

$32 \mathrm{~S}$ cotton knitted fabric with direct tanning resistance to black $\mathrm{G}$ dyeing with active Tibetan blue $\mathrm{BF}$, impregnated with DM-2589N 30g/L, was roasted at $150^{\circ} \mathrm{C}$ for $60,90,120,180 \mathrm{~s}$, respectively. The color fastness to wet friction was tested in Table 3 after wetting.

Table 3 showed that when the curing time was extended to $90 \mathrm{~s}$, the rubbing color fastness was improved. And when the curing time was up to $120 \mathrm{~s}$, there was no improvement in wet rubbing color fastness, which indicated that the wet rubbing fastness lifting agent was fully crosslinked with the fiber at this time. Therefore, the baking time was $120 \mathrm{~s}$.

Table 3. Effect of baking time on rubbing colour fastness.

\begin{tabular}{llll}
\hline \multirow{2}{*}{ Curing time } & \multicolumn{2}{l}{ Dyeing cotton fabric with active Tibetan blue BF } & Direct black G dyed cotton fabric \\
\cline { 2 - 4 } & Dry rubbing colour fastness & Wet rubbing colour fastness & Dry rubbing colour fastness \\
\hline $60 \mathrm{~S}$ & $4-5$ & $3-4$ & $4-5$ \\
$90 \mathrm{~S}$ & $4-5$ & $4-$ & $4-5$ \\
$120 \mathrm{~S}$ & $4-5$ & 4 & $4-5$ \\
$180 \mathrm{~S}$ & $4-5$ & 4 & $4-5$ \\
\hline
\end{tabular}

\subsection{Lifting Effect of Different Fabric Rubbing Color Fastness}

Several common pure cotton fabrics dyed with active Tibetan green BF, direct resistance to sun black G were impregnated with DM-2589N $30 \mathrm{~g} / \mathrm{L}$, baked at $150^{\circ} \mathrm{C}$ for $120 \mathrm{~s}$. The color fastness to wet friction was tested in Table 4 after wetting.

Table 4. Colour fastness of DM-2589N to friction on different fabrics.

\begin{tabular}{|c|c|c|c|c|c|}
\hline \multirow[b]{2}{*}{ Textile } & & \multicolumn{2}{|c|}{ Dyeing cotton fabric with active Tibetan blue BF } & \multicolumn{2}{|c|}{ Direct black $\mathbf{G}$ dyed cotton fabric } \\
\hline & & Dry rubbing colour fastness & $\begin{array}{l}\text { Wet rubbing colour } \\
\text { fastness }\end{array}$ & $\begin{array}{l}\text { Dry rubbing colour } \\
\text { fastness }\end{array}$ & $\begin{array}{l}\text { Wet rubbing colour } \\
\text { fastness }\end{array}$ \\
\hline \multirow{2}{*}{ Yarn card } & Before finishing & $3-4$ & $1-2$ & $3-4$ & $1-2$ \\
\hline & After finishing & $4-5$ & 4 & $4-5$ & 4 \\
\hline \multirow{2}{*}{ Popeline } & Before finishing & $3-4$ & 2 & $3-4$ & 2 \\
\hline & After finishing & $4-5$ & $4-5$ & $4-5$ & $4-5$ \\
\hline \multirow{2}{*}{ Cotton standard lining } & Before finishing & $3-4$ & $1-2$ & $3-4$ & $1-2$ \\
\hline & After finishing & $4-5$ & $4-5$ & $4-5$ & $4-5$ \\
\hline \multirow{2}{*}{ Worsted cloth } & Before finishing & 3 & 1 & 3 & 1 \\
\hline & After finishing & $4-5$ & 4 & $4-5$ & 4 \\
\hline \multirow{2}{*}{ Garrison cloth } & Before finishing & $2-3$ & 1 & $2-3$ & 1 \\
\hline & After finishing & $4-5$ & 4 & $4-5$ & 4 \\
\hline \multirow{2}{*}{ Lamp pile } & Before finishing & $1-2$ & 1 & $1-2$ & 1 \\
\hline & After finishing & 4 & $3-4$ & 4 & $3-4$ \\
\hline
\end{tabular}

Table 4 showed that DM-2589N can improve the wet rubbing color fastness of common cotton fabrics (including pile fabrics) to 3-4 or above. It manifested that DM-2589N can improve wet rubbing fastness of all kinds of cotton fabrics. 


\subsection{Enhancement Effect of Rubbing Fastness of Fabrics Dyed with Different Reactive Dyes}

Active turquoise blue (BES), active Tibetan blue (BF), active black (RG), super red RW stained $32 \mathrm{~S}$ cotton knitted fabrics, baked at $150^{\circ} \mathrm{C}$ for $120 \mathrm{~s}$ at $30 \mathrm{~g} / \mathrm{L}$ DM-2589N, were tested for wet friction color fastness and color difference $\mathrm{E}$ in Table 5 after wetting.

Table 5. Color fastness to friction of fabrics dyed with different reactive dyes using DM-2589N.

\begin{tabular}{lllll}
\hline Textile & & Delta E value & Dry rubbing colour fastness & Wet rubbing colour fastness \\
\hline \multirow{2}{*}{ Reactive emerald blue BES dyed fabric } & Before finishing & $/$ & $3-4$ & $1-2$ \\
& After finishing & 0.74 & $4-5$ & 3 \\
Reactive Tibetan blue BF dyed fabric & Before finishing & $/$ & $4-5$ & 1 \\
& After finishing & 0.66 & 3 & $4-5$ \\
Reactive black RG dyed fabric & Before finishing & $/$ & $1-2$ & 4 \\
& After finishing & 0.51 & $4-5$ & 1 \\
Reactive super red RW dyed fabric & Before finishing & $/$ & 4 \\
\hline
\end{tabular}

Table 5 showed that DM 2589N, a lifting agent for rubbing fastness, can improve the wet rubbing fastness of dyed fabrics with different reactive dyes. But all of them can reach 4 grades, which meet the requirement of wearing. This indicated that DM-2589N was used in the finishing of dark fabrics and had no selectivity for reactive dyes.

\subsection{Effect of Direct, Vulcanized, Vat Dyestuff Dyeing}

$32 \mathrm{~S}$ cotton knitted fabrics dyed with direct dyes, sulfur dyes and vat dyes respectively, finished with DM-2589N $30 \mathrm{~g} / \mathrm{L}$, were tested for color fastness to wet rubbing $\mathrm{E}$ as shown in Table 6.

Table 6. Color fastness to friction of direct, vulcanized, vat dyed fabrics with DM-2589N.

\begin{tabular}{|c|c|c|c|c|}
\hline Textile & & Delta E value & Dry rubbing colour fastness & Wet rubbing colour fastness \\
\hline \multirow{2}{*}{ Direct black G } & Before finishing & I & 3 & 1 \\
\hline & After finishing & 0.68 & $4-5$ & 4 \\
\hline \multirow{2}{*}{ Direct red 4BS } & Before finishing & / & 4 & 2 \\
\hline & After finishing & 0.75 & $4-5$ & 4 \\
\hline \multirow{2}{*}{ Direct blue BRL dyeing fabric } & Before finishing & / & $3-4$ & 1 \\
\hline & After finishing & 0.36 & $4-5$ & 4 \\
\hline Sulphur black & Before finishing & / & $1-2$ & 1 \\
\hline \multirow{2}{*}{ Vat Brown BR } & After finishing & / & 3 & 1 \\
\hline & Before finishing & 0.52 & $4-5$ & 4 \\
\hline \multirow{2}{*}{ Reduced black RB } & After finishing & / & 2 & 1 \\
\hline & Before finishing & 0.45 & $4-5$ & 4 \\
\hline
\end{tabular}

Table 6 showed that DM-2589N dyestuff, vulcanized dye and vat dyestuff can improve the dry and wet rubbing fastness significantly; wet rubbing fastness was 3 - 4, dry rubbing fastness was 4-5, and the finishing had little effect on the color and light of the fabric.

\subsection{Color Fastness to Friction of Softener and DM 2589N in the Same Bath}

On $32 \mathrm{~S}$ cotton knitted fabric dyed with active BF, super red RW, the softener 20g/L DM-2589N 30g/L was treated in the same bath. The color fastness to wet friction was tested in Table 7.

Table 7. Colour fastness to friction of softener and DM-2589N in the same bath.

\begin{tabular}{llll}
\hline \multirow{2}{*}{ Softener + DM-2589N } & \multicolumn{2}{l}{ Dyeing cotton fabric with active Tibetan blue BF } & \multicolumn{2}{l}{ Reactive Super Red RW dyeing of Cotton fabrics } \\
\cline { 2 - 4 } & $\begin{array}{l}\text { Dry rubbing colour } \\
\text { fastness }\end{array}$ & $\begin{array}{l}\text { Wet rubbing colour } \\
\text { fastness }\end{array}$ & $\begin{array}{l}\text { Dry rubbing colour } \\
\text { fastness }\end{array}$ \\
\hline Blank space & 3 & 1 & $1-2$ \\
fastness
\end{tabular}

Table 7 showed that the effects of different softeners on the DM-2589N rubbing fastness were different, indicating that DM-2589N had a certain selectivity to softener, in which silicone oil 0127 and DM-2589N in the same bath had no effect on dry and wet rubbing fastness. Dry and wet rubbing color fastness can be raised to level 4, while achieving soft and smooth feel. 


\subsection{Effect of Active Fixing Agent, Softener and DM-2589N on the Improvement of Friction Color Fastness in the Same Bath}

On $32 \mathrm{~S}$ cotton knitted fabric dyed with active BF, super red RW, fixing agent DM-2517 10g/L, silicone oil $0127 \mathrm{~g} / \mathrm{L}$, DM-2589N 30g/L in the same bath, the color fastness of each color fastness was reported in Table 8 and 9.

Table 8. Color fastness to wet friction of fixing agent and DM-2589N in the same bath.

\begin{tabular}{llll}
\hline & \multicolumn{2}{l}{ Dyeing cotton fabric with active Tibetan blue BF } & \multicolumn{2}{l}{ Reactive Super Red RW dyeing of Cotton fabrics } \\
\cline { 2 - 4 } & $\begin{array}{l}\text { Dry rubbing colour } \\
\text { fastness }\end{array}$ & $\begin{array}{l}\text { Wet rubbing colour } \\
\text { fastness }\end{array}$ & $\begin{array}{l}\text { Dry rubbing colour } \\
\text { fastness }\end{array}$ \\
\hline Blank space & 3 & 1 & $1-2$ \\
fastness
\end{tabular}

Table 9. Color fastness to soaping and sweat stains with DM-2589N in the same bath.

\begin{tabular}{|c|c|c|c|c|c|c|}
\hline & \multicolumn{3}{|c|}{ Dyeing cotton fabric with active Tibetan blue BF } & \multicolumn{3}{|c|}{ Reactive Super Red RW dyeing of Cotton fabrics } \\
\hline & soaping & hidrolic acid & sweat stain & soaping & hidrolic acid & sweat stain \\
\hline Blank space & 1 & $1-2$ & 1 & 1 & 1 & 1 \\
\hline DM-2589N & $1-2$ & 2 & 2 & $1-2$ & 2 & 2 \\
\hline DM-2517+DM-2589N & $4-5$ & $4-5$ & $4-5$ & $4-5$ & $4-5$ & $4-5$ \\
\hline DM-2517+ $0127+\mathrm{DM}-2589 \mathrm{~N}$ & $4-5$ & $4-5$ & $4-5$ & $4-5$ & $4-5$ & $4-5$ \\
\hline
\end{tabular}

Table $8 / 9$ showed that the rubbing fastness lifting agent DM $2589 \mathrm{~N}$ was treated in the same bath with the fixing agent DM 2517 and the silicone oil 0127. The three processes of hand feeling finishing, fixing and wet rubbing finishing are combined into one process. After finishing, the fastness to rubbing, soaping and perspiration can reach grade 4 or above, It simplifies the production process of dyeing plant and helps to improve production efficiency.

\section{Production Practice of Dyeing Factory}

The technical indexes of DM-2589N met the requirements of production, and then the samples were produced in 2 printing and dyeing factories in Guangdong area. Production and use of equipment: Hong Kong CHTC Fong's Industries Company Limited Men Fushi molding machine.

\subsection{Dyeing Plant Production Process}

\subsubsection{Use of Fabric and Additive Formulations}

Table 10. Use of fabrics and Additives.

\begin{tabular}{|c|c|c|c|c|}
\hline & Dyeing factory $\mathrm{H}$ & & Dyeing factory $\mathbf{C}$ & \\
\hline Fabric varieties and colors & $\begin{array}{l}\text { Black cotton cloth with big } \\
\text { eyes and single bead }\end{array}$ & $\begin{array}{l}\text { Black cotton left twill } \\
\text { double garb cloth }\end{array}$ & $\begin{array}{l}\text { Blue long-staple cotton } \\
\text { yarn flat print }\end{array}$ & Dark red mercerized yarn \\
\hline Cloth weight & $\begin{array}{l}23 \text { pieces of cloth, weight of } \\
\text { cloth: } 540.76 \mathrm{~kg}\end{array}$ & $\begin{array}{l}9 \text { pieces of cloth, weight of } \\
\text { cloth: } 246.99 \mathrm{~kg}\end{array}$ & $\begin{array}{l}4 \text { pieces of cloth, weight } \\
\text { of cloth: } 96.40 \mathrm{~kg}\end{array}$ & $\begin{array}{l}46 \text { pieces of cloth, weight of } \\
\text { cloth: } 1019.10 \mathrm{~kg}\end{array}$ \\
\hline DM-2589N & $30 \mathrm{~g} / \mathrm{L}$ & $40 \mathrm{~g} / \mathrm{L}$ & $30 \mathrm{~g} / \mathrm{L}$ & $30 \mathrm{~g} / \mathrm{L}$ \\
\hline Silicon oil 0127 & $15 \mathrm{~g} / \mathrm{L}$ & $15 \mathrm{~g} / \mathrm{L}$ & & \\
\hline Nonionic permeant DM-1230 & & & $3 \mathrm{~g} / \mathrm{L}$ & $3 \mathrm{~g} / \mathrm{L}$ \\
\hline Rolling surplus rate & $78.5 \%$ & $83.2 \%$ & $85.6 \%$ & $81.4 \%$ \\
\hline
\end{tabular}

\subsubsection{Production Engineering}

The machine was impregnated and rolled and baked at $150^{\circ} \mathrm{C}$. The speed of the machine was between 15 to $20 \mathrm{~m} / \mathrm{min}$.

\subsection{Results of Mass Production}

Observe the cloth effect of the above four kinds of fabrics and test the color fastness and the color difference value of the friction. The recorded results were reported in Table 11.

Table 11. Production results

\begin{tabular}{|c|c|c|c|c|c|}
\hline & & Black bead cloth & Black cloth & Treasure blue flat grain & Dark red flat grain \\
\hline \multirow{2}{*}{ Dry rubbing colour fastness } & Before finishing & 2 & $1-2$ & $1-2$ & $1-2$ \\
\hline & After finishing & $4-5$ & $4-5$ & $4-5$ & $4-5$ \\
\hline \multirow{2}{*}{ Wet rubbing colour fastness } & Before finishing & $1-2$ & 1 & $1-2$ & 1 \\
\hline & After finishing & 4 & $3-4$ & $3-4$ & $3-4$ \\
\hline Value of chromatism & & 0.48 & 0.53 & 0.57 & 0.61 \\
\hline Oil spot condition & & not have & not have & not have & not have \\
\hline
\end{tabular}




\begin{tabular}{|c|c|c|c|c|}
\hline & Black bead cloth & Black cloth & Treasure blue flat grain & Dark red flat grain \\
\hline $\begin{array}{l}\text { Color spot } \\
\text { Feel }\end{array}$ & $\begin{array}{l}\text { not have } \\
\text { good }\end{array}$ & $\begin{array}{l}\text { not have } \\
\text { good }\end{array}$ & $\begin{array}{l}\text { not have } \\
\text { secondary }\end{array}$ & $\begin{array}{l}\text { not have } \\
\text { secondary }\end{array}$ \\
\hline
\end{tabular}

\subsection{Large Production Result Analysis}

The large production practice showed that the rubbing fastness lifting agent DM-2589N significantly improved the friction color fastness of dyed fabrics. Meanwhile, the production continuity was good, the reproducibility was good, and the finishing had little influence on the color and light. The same bath finishing with silicon oil 0127 not only improved the quality of the processed cloth seed, but also simplified the production process and the comprehensive economic benefit.

\section{Conclusion}

The main results were as follows:

(1) DM-2589N was used in the finishing of dark fabrics. It had no selectivity for dyes, and can improve the wet rubbing fastness of reactive dyes, direct dyes, sulphide dyes and vat dyes to 3 or higher grade. DM-2589N was used in the finishing of various dark cotton fabrics such as yarn card, poplin, plain fabric, bead cloth, abrasive cloth, sanitary cloth and pile fabric. It had excellent effect on improving the wet rubbing color fastness of fabric, and had little influence on the color and feel of fabric.

(2) DM-2589N had no phosphorus, formaldehyde, heavy metal, organohalide and $\mathrm{REACH}$ regulations. The $\mathrm{pH}$ value of the working solution was not adjusted when it was put into use It combines hand feeling, fixing and wet rubbing with fixing agent DM-2517 and silicone oil 0127 in the same bath finishing process. After the same bath finishing, the color fastness of the fabric to friction, soaping and perspiration can reach grade 4 or more, which not only improves the wearing performance of the dark fabric, but also simplifies the production process of the dyeing plant, and has good economic and social benefits.

\section{Foundation Project}

Hunan Natural Science Foundation supported Project (2018JJ4049); Hunan University Innovation platform Open Fund Project (16K023)

\section{References}

[1] Wang Ya-jun. Development and application of $\mathrm{CW}$ for improving wet rubbing fastness. Hebei University of Science and Technology.
[2] Li XP, Wan Guangfeng, et al. Synthesis and application of wet rubbing fastness promoters for reactive dyes $[\mathrm{J}]$. Journal of Wuhan Textile University: 26 (6): 14-18.

[3] Liu Qingyan, he Jiangping, et al. Study on the applied properties of rubbing fastness promoters for reactive dyestuff dyed fabrics [J]. Printing and dyeing Additives: 26 (5): 29-32.

[4] Daemi 11, Barikani M, Barmar M. Compatible Compositions Based on Aqueous Polyurethane Dispersions and Sodium Alginate [J]. Carbohydrate Polymers, 2013, 92 (1):490-496.

[5] Mao Qing-hui, Mao Zhi-ping, et al. Promotion of wet rubbing fastness of dark flannel-based fabrics [J]. Printing and dyeing Additives: 200623 (5): 40-43.

[6] Li Aqian. Study on improving wet rubbing fastness of reactive dyestuff fabrics with deep color. (master thesis).

[7] Ji Wanli's application of DC-79 in vulcanized dyeing [J]. Printing and dyeing (2012 No. 12): 32-34.

[8] Luo Ming-yong, he Jiangping, et al. Development and application of waterborne polyurethane fastness to wet friction [J]. Printing and dyeing (2009 No. 7): 1-5.

[9] Tong Dong-feng, Liu Xue, Dong, Chao-hong, Liu Jie. Synthesis and Application of Polyurethane Modified Organic Silicone Wet Rubbing Fastness Improver [J]. Journal of Donghua University (Eng. Ed) Vol. 32, No. 3 (2015) 515-519.

[10] Shuling Cui. Synthesis of MDI-based WPU wet-rubbing fastness improver. Pigment \& Resin Technology [J]. Vol. 44 Iss 3 (2015): 125- 130

[11] Zhou, C. and Xu, J. X., Regioselective nucleophilic ring-opening reactions of asymmetric epoxy ethane [J]. Progress in Chemistry, Vol. 23 No. 1 (2011): 174-189.

[12] Duan Ya-ping, Yao Ti-ming. Treatment method for improving both the wet rubbing and the hand feeling of colorfastness to indigo denim [J]. Textile Auxiliaries, Vol. 35 (2018 No. 7): 49-54.

[13] Bureau of Technical Supervision of People's Republic of China (2008), "GB/T 3920-2008 textiles-tests for colour fastness colour fastness to rubbing", available at: http://www.zbgb.org/2/StandardDetail518091.htm.

[14] Bureau of Technical Supervision of People's Republic of China (2008), "GB/T 3921-2008 textiles-tests for colour fastness Colour fastness to washing with soap", available at: http://www.zbgb.org/2/StandardDetail518097.htm.

[15] Bureau of Technical Supervision of People's Republic of China (2013), "GB/T 3922-2013 textiles-tests for colour fastness colour fastness to perspiration", available at: http://www.zbgb.org/2/StandardDetail2425520.htm. 